\title{
MATERIAL DIDÁTICO VIRTUAL LIVRE PARA O \\ ENSINO E A APRENDIZAGEM DE ITALIANO NO ÂMBITO DOS CENTROS DE ESTUDOS DE LÍNGUAS DO ESTADO DE SÃO PAULO: CAMINHOS DA PEDAGOGIA PÓS-MÉTODO
}

\section{FREE ${ }^{1}$ VIRTUAL MATERIALS FOR ITALIAN TEACHING AND LEARNING IN THE CONTEXT OF LANGUAGE STUDIES CENTERS OF THE STATE OF SÃO PAULO: PATHS OF THE POST METHOD PEDAGOGY}

Rômulo Francisco de Souza*

\section{RESUMO}

Discutimos a problemática do material didático no contexto dos cursos de italiano dos Centros de Estudos de Línguas (CEL) do Estado de São Paulo, deflagrando, embasados em Peleteiro (2015) e em Pinheiro (2013), a sua vocação para a utilização de materiais didáticos essencialmente personalizados e personalizáveis. Frente a essa questão, caracterizamos materiais didáticos de natureza virtual e livre, discutindo a sua correlação com a pedagogia pós-método, e propomos os materiais didáticos dessa natureza como os mais adequados para o contexto dos CEL, uma vez que são, essencialmente, personalizáveis (SOUZA, 2014). Trata-se da nossa principal hipótese de trabalho. Sugerimos requisitos para o design de repositórios virtuais que consideramos adequados para o desenvolvimento e a utilização de materiais didáticos de natureza virtual e livre. Nossas sugestões foram elaboradas a partir da análise do CURRÍCULO+, repositório digital da Secretaria de Educação do Estado de São Paulo que consideramos inadequado às demandas relativas ao uso e à produção de materiais didáticos em uma perspectiva pós-método, ou seja, ao uso e à produção de materiais didáticos de natureza virtual e livre (SOUZA, 2014). A inadequação consiste, principalmente, no fato de se tratar de um repositório centrado no currículo, e não no professor-autor e em suas demandas locais, advindas dos contextos em que atua. Discorremos, enfim, sobre a metodologia de produção de material didático na perspectiva da pedagogia pós-médodo, que experimentamos e buscamos aprimorar em nossa pesquisa. Defendemos que a produção de material didático na perspectiva da pedagogia pós-método envolve o estabelecimento e a utilização de princípios, ou quadros de referência, compatíveis com o estado atual do conhecimento, coerentes, compreensíveis, neutros em relação a métodos e de caráter não prescritivo. Fundamentamo-nos em Kumaravadivelu (2006b) e Tomlinson

\footnotetext{
* Universidade de São Paulo, São Paulo (SP), Brasil. romulosouza@usp.br 1. As in freedom.
} 
(2016). Consideramos que se trata, ademais, de uma prática que também reflete, de algum modo, os parâmetros da particularidade, da praticabilidade e da possibilidade.

Palavras-chave: Pós-método; material didático virtual livre; Centro de Estudos de Línguas do Estado de São Paulo.

\section{ABSTRACT}

We discuss the problem of materials in the context of the Italian language courses of the Language Studies Centers (CEL) of the State of São Paulo (Brazil). Based on Peleteiro (2015) and Pinheiro (2013), we perceive their vocation for the use of materials that are essentially personalized and customizable. Facing this question, we characterized virtual and free nature materials, discussing their correlation with post-method pedagogy (SOUZA 2014). We propose this kind of materials as the most suitable for the context of the CEL, since they are essentially customizable. This is our main working hypothesis. We point out and suggest requirements for the design of virtual repositories that we consider appropriate for the development and use of virtual and free nature materials. Our suggestions were elaborated from the analysis of CURRICULUM +, the digital repository of the Department of Education of the State of São Paulo, which we considered inappropriate to the demands related to the use and production of materials in a post-method perspective, that is, to the use and production of virtual and free nature materials (SOUZA, 2014). The inadequacy consists, mainly, of being the repository centered in the curriculum, and not in the teacherauthor and their local demands, coming from the contexts in which they act. Finally, we discuss the methodology of the production of materials in the perspective of post-method pedagogy, which we try to improve in our research. We argue that the production of materials in the perspective of post-method pedagogy involves the establishment and use of principles, or frames of reference, compatible with the current state of knowledge, coherent, comprehensible, method-neutral and non-prescriptive. We are based on Kumaravadivelu (2006b) and Tomlinson (2016). We consider that it is, in addition, a practice that also reflects, in some way, the parameters of particularity, practicality and possibility.

Keywords: Post-method; free virtual materials; Language Studies Centers of the state of São Paulo.

\section{APRESENTAÇÃO}

Neste artigo, trazemos para debate os aspectos essenciais de nossa pesquisa de pós-doutorado, em andamento, junto à Faculdade de Filosofia, Letras e Ciências Humanas da Universidade de São Paulo (FFLCH-USP), com apoio do Programa Nacional de Pós-doutorado da CAPES (PNPD-CAPES). Apresentamos, também, os resultados parciais da investigação, os quais obtivemos a partir dos nossos esforços de compreensão do contexto dos Centros de Estudos de Línguas (CEL) do Estado de São Paulo, especialmente no que se refere à questão do material didático e da possibilidade de implementação da pesquisa e da utilização de Material Didático Virtual Livre nesse contexto. 
Dessa forma, na seção 2, apresentamos uma visão geral da nossa pesquisa. $\mathrm{Na}$ seção 3, situamos o ensino de italiano no contexto dos CEL, reunindo dados sobre o projeto e trazendo para debate aspectos de suas origens e de sua organização atual. Na seção 4, apresentamos e discutimos a problemática do material didático no contexto dos cursos de italiano dos CEL, deflagrando a sua vocação para a utilização de materiais didáticos essencialmente personalizados e personalizáveis. Para tanto, nos fundamentamos em Peleteiro (2015) e em Pinheiro (2013). Na seção 5, caracterizamos materiais didáticos de natureza virtual e livre, discutindo a sua correlação com a pedagogia pós-método, conforme SOUZA (2014), e propomos esse tipo de material didático como o mais adequado para o contexto dos CEL. Trata-se da nossa principal hipótese de trabalho. Na seção 6, apontamos e sugerimos alguns requisitos para o design de repositórios virtuais que consideramos adequados para o desenvolvimento e a utilização de materiais didáticos de natureza virtual e livre. Nossas sugestões foram elaboradas a partir da análise do CURRÍCULO+, repositório digital da Secretaria de Educação do Estado de São Paulo. Consideramos que esse repositório não se adequa às demandas relativas ao uso e à produção de materiais didáticos em uma perspectiva pós-método, ou seja, ao uso e à produção de materiais didáticos de natureza virtual e livre, uma vez que é centrado no currículo, e não no professor-autor e em suas demandas locais, advindas dos contextos em que esse profissional atua (SOUZA, 2014). Na seção 7, enfim, discorremos sobre a metodologia de produção de material didático na perspectiva da pedagogia pós-médodo, que experimentamos e buscamos aprimorar em nossa pesquisa. Defendemos que a produção de material didático na perspectiva da pedagogia pós-método envolve o estabelecimento e a utilização de princípios, ou quadros de referência, compatíveis com o estado atual do conhecimento, coerentes, compreensíveis, neutros em relação a métodos e de caráter não prescritivo, com base em Kumaravadivelu (2006b) e em Tomlinson $(2010$; 2016). Ademais, trata-se de uma prática que também reflete, de algum modo, os parâmetros da particularidade, da praticabilidade e da possibilidade.

\section{VISÃO GERAL DA PESQUISA}

Propomos, em nossa pesquisa, investigar os Problemas de Ensino (ORTALE, 2010, 2011) relacionados à produção de Material Didático Virtual Livre (SOUZA, 2014) de língua italiana como língua adicional no contexto dos Centros de Estudos de Línguas (CEL) da rede pública de ensino do Estado de São Paulo, com vistas à formação de repositórios digitais online (NASCIMENTO, 2009; ABED, s.d.), 
livres e abertos, que servirão de apoio tanto para as aulas presenciais dos referidos centros quanto para o estudo autônomo, dentro ou fora dos CEL, caracterizado pela autoaprendizagem de língua italiana e pela autoformação docente continuada de professores e professoras dessa língua. Pressupomos, dessa forma, o repositório digital online, aberto e livre, como canal e lugar de ensino e aprendizagem, superando a noção de repositório digital como simples espaço de armazenamento e organização de coleções de itens, objetos educacionais, Material Didático Virtual Livre ou Recursos Educacionais Abertos.

Conforme debatemos em SOUZA (2014), a partir dessa investigação será possível, entre outras coisas, estabelecer temas, competências ou habilidades que poderão balizar o desenvolvimento de programas de formação continuada, centrada na produção de material didático (TOMLINSON, 2003) para os próprios docentes de língua italiana dos CEL.

A metodologia que apresentamos para essa investigação está arraigada na prática do professor de idiomas e foi amplamente experimentada em nosso percurso de doutoramento (SOUZA, 2014). Trata-se de uma proposta metodológica que integra investigação e formação, em uma dinâmica sinergética, conforme discutimos em SOUZA $(2016$; 2017), a partir dos Problemas de Ensino apresentados pelos professores, ou seja, com base em sua prática (ORTALE, 2010; 2011).

A metodologia de produção de Material Didático Virtual Livre relacionada ao aspecto formativo da investigação envolve, essencialmente, o desenvolvimento de habilidades e competências teórico-operativas (DIADORI, 2001) e a noção de design de material didático de idiomas em uma perspectiva pós-método. Essa noção, em linhas de síntese, está ancorada na prática docente, nas demandas e peculiaridades dos contextos de aplicação, e na utilização de princípios ou quadro teóricos de referência, coerentes e compreensíveis, compatíveis com o estado atual do conhecimento, neutros em relação aos métodos, porém, não desconectados de teorias (KUMARAVADIVELU, 1994; 2003; 2006a; 2006b). Ela se aproxima, ademais, do nosso ponto de vista, da noção de elaboração de material didático baseada em princípios, conforme Tomlinson (1998, 2010, 2016), com a qual também dialogamos.

Consideramos, portanto, que a implementação desta pesquisa poderá fomentar a produção de material didático de língua italiana para os Centros de Estudos de Línguas, uma vez que forma os seus professores para essa tarefa, ao mesmo tempo em que investiga os Problemas de Ensino a ela correlacionados. 


\section{OS CENTROS DE ESTUDOS DE LÍNGUAS (SP) E O ENSINO DE ITALIANO}

Os Centros de Estudos de Línguas (CEL) do Estado de São Paulo foram criados em 1987 por meio do Decreto Estadual no 27.270, de 10 de agosto de 1987 (SÃO PAULO, 1987), visando ao fortalecimento da integração latinoamericana (CALLEGARI, 2008; SANTOS, 2011; GASPARELO, 2009). Entre os seus objetivos, conforme consta no decreto, estão: a intenção de proporcionar diferentes "oportunidades de desenvolvimento de novas formas de expressão linguística" (SÃO PAULO, 1987) pelos alunos das escolas públicas estaduais; o enriquecimento do currículo e a superação do monolinguismo vigente nesse contexto (SÃO PAULO, 1987). Na ocasião, o espanhol era a única língua presente (CALLEGARI, 2008; SANTOS, 2011; GASPARELO, 2009).

No decorrer dos anos, os objetivos essenciais dos CEL foram mudando em relação à fase de implantação, não se limitando à questão da integração latinoamericana (CALLEGARI, 2008) e, consequentemente, ao interesse específico pelo espanhol e pela cultura latino-americana (GASPARELO, 2009). Dessa forma, em 1988, a resolução SE n 193 de agosto de 1988 tornou o ensino do castelhano preferencial, e não mais exclusivo, no contexto dos CEL (SÃO PAULO, 1988). A partir daí, outras línguas estrangeiras foram incluídas no projeto. Concomitantemente, novos centros foram criados (SANTOS, 2011).

O ensino de língua italiana no âmbito dos CEL teve início apenas em 1989, dois anos depois de sua criação, segundo dados da Coordenadoria de Gestão da Educação Básica apud Rocha (2016). Desde então, o ensino desse idioma vem sendo ofertado regularmente. Vale ressaltar, nesse caso, a presença e a ação das associações de professores de italiano, no Estado de São Paulo, no sentido de incentivar a inserção dessa língua no âmbito dos CEL. De modo geral, de fato, associações de professores de idiomas e entidades representativas dos países cujas línguas estão presentes nos centros têm celebrado parcerias com a Secretaria de Educação do Estado de São Paulo no sentido de contribuir da melhor maneira possível. Ressaltamos, por exemplo, a FECIBESP2 ${ }^{2}$ para o italiano, e o Instituto Goethe para o alemão.

No primeiro semestre de 2017, segundo a Secretaria de Educação do Estado de São Paulo (SÃO PAULO, 2016a), os CEL ofereceram um total de 6 (seis) línguas estrangeiras modernas. De fato, além do italiano, os alunos poderiam escolher entre o espanhol, o inglês, o francês, o alemão ou o japonês (QUADRO 1).

2. Federação das Entidades Culturais Ítalo-brasileiras do Estado de São Paulo 
Quadro 1. Organização atual dos cursos de idiomas doS CEL - 2016 / 2017

\begin{tabular}{ll}
\hline Línguas ofertadas & Inglês, espanhol, italiano, francês, alemão, japonês (1/2017) \\
Duração & Inglês: 1 ano \\
& Italiano e demais idiomas: 3 anos (6 semestres) \\
Número de aulas & Inglês: 160 aulas \\
& Italiano e demais idiomas: 480 aulas \\
Público-alvo & Inglês: ensino médio \\
Realização & Italiano e demais idiomas: ensino fundamental a partir do $7^{\circ}$ ano. \\
\hline
\end{tabular}

Fonte: Ortale e Zorzan (2013); São Paulo (2016a; 2016b, 2016c).

A organização atual dos cursos dos CEL prevê um perfil diferenciado entre o inglês e os demais idiomas, incluindo o italiano. Conforme destacamos no QUADRO 1, enquanto o curso de inglês é ofertado para o ensino médio, com duração de um ano e um total de 160 aulas, o italiano e os outros idiomas são oferecidos para alunos e alunas a partir do sétimo ano do ensino fundamental, abrangendo um período de 3 anos e perfazendo um total de 480 aulas (ORTALE e ZORZAN, 2013; SÃO PAULO, 2016a, 2016b; 2016c).

Quadro 2. 0 italiano nos CEL em números: unidades, aprendizes e docentes em 2/2016

\section{Unidades}

Número total de CEL

Número total de CEL (italiano)*

*Distribuídos em 26 cidades do Estado de São Paulo

Alunos e alunas

Número total (aproximado) de alun@s nos CEL

59.461

Total: 1.370

Número (aproximado)de alun@snos CEL (italiano)

$2^{\mathrm{a}}$ a $6^{\mathrm{a}}: 1.126$

Sábados: 244

Docentes

Número total (aproximado) de docentes dos CEL

850

Número total (aproximado) de docentes dos CEL (italiano)

40

Fonte: SÃO PAULO (2016c) 
Em termos numéricos, conforme a Secretaria de Educação do Estado de São Paulo (SÃO PAULO, 2016c), no segundo semestre de 2016, o italiano foi ofertado em 37 dos 212 CEL da rede estadual, contando com 40 docentes - de um total de 850 , considerando-se todos os idiomas ofertados - e um número aproximado de 1.370 alunos e alunas, entre o total, também aproximado, de 59.461 aprendizes matriculados para todos os idiomas nos CEL. Reunimos esses dados no QUADRO 2.

\section{ITALIANO NOS CEL: A QUESTÃO DO MATERIAL DIDÁTICO E A VOCAÇÃO PARA UMA PEDAGOGIA PÓS-MÉTODO}

Peleteiro (2015) aponta a produção de material didático como uma das principais demandas dos cursos de italiano dos CEL. A autora, ao analisar uma iniciativa de produção de material didático para o ensino de italiano no contexto dos Centros de Estudos de Línguas, deflagra uma série de tendências e características que podem indicar a criação de material didático ad hoc, personalizado e personalizável, gerenciado e produzido pelos próprios docentes - ou com a sua participação ativa no processo - como a solução mais adequada para o apoio ao ensino de língua italiana nesse contexto.

Entre os fatores reunidos por Peleteiro (2015), destacamos, por exemplo: a presença de turmas multisseriadas; a impossibilidade de compra de material didático impresso de língua italiana, seja pelo seu alto custo, seja por questões legais, relativas às políticas de compra e utilização de material didático na rede de ensino pública; a dificuldade de encontrar materiais adequados ao seu público-alvo, ou seja, em sua maioria, adolescentes e crianças, entre outros.

Quadro 3. Tendências e características para o material didático nos cursos de italiano dos CEL

- $\quad$ Produzido localmente (ad hoc).

- Personalizado e personalizável (respeitando as particularidades de cada região do Estado de São Paulo).

- Gerenciado e produzido pelas próprias professoras e pelos próprios professores; ou com a sua participação ativa no processo.

- Distribuído gratuitamente.

- Disponibilizado online.

Fonte: adaptado de Peleteiro (2015) e Pinheiro (2013). 
Corrobora a identificação e o delineamento desse cenário, a proposta de produção de material didático de Pinheiro (2013) para o apoio aos cursos de italiano dos Centros de Estudos de Línguas, uma vez que sugere, como características para esse material didático, entre outras: a sua distribuição gratuita aos alunos e aos professores dos CEL; a comercialização proibida; a disponibilização de uma versão online; e a necessidade de adaptação constante desse material didático pelas equipes pedagógicas dos $\mathrm{CEL}$, respeitando as particularidades de cada região do Estado de São Paulo. O autor destaca, ainda, a participação ativa dos professores na elaboração do material didático como elemento-chave para o sucesso desse empreendimento, uma vez que esses professores conhecem o público-alvo dos CEL e suas reais necessidades.

Compreendemos que as demandas e tendências apresentadas por Peleteiro (2015) e Pinheiro (2013) parecem deflagrar uma vocação dos cursos de italiano dos CEL para uma pedagogia de caráter pós-método.

Conforme discutimos e parafraseamos em Souza (2014), em linhas de síntese, Kumaravadivelu (2001) e Kumaravadivelu (2006b), percebem a pedagogia pós-método como um sistema tridimensional composto por três parâmetros pedagógicos inter-relacionados: os parâmetros da particularidade, da praticabilidade e da possibilidade.

O parâmetro da particularidade está relacionado a uma "compreensão verdadeira das particularidades linguísticas, socioculturais e políticas locais" (KUMARAVADIVELU, 2001, p. 544), ou seja, a uma opção pedagógica sensível ao contexto, que, portanto, rejeita a adoção de princípios genéricos e predeterminados com o objetivo de cumprir objetivos também genéricos e predeterminados.

O parâmetro da praticabilidade, por sua vez, está relacionado à rejeição de um modelo artificial marcado pela relação dicotômica entre aquele que elabora a teoria - ou seja, o teórico - e aquele que consome teoria - o docente. Com efeito, na perspectiva da pedagogia pós-método, os professores são encorajados a "teorizar a partir de sua prática e praticar o que teorizaram" (KUMARAVADIVELU, 2001, p. 544).

O parâmetro da possibilidade, enfim, está relacionado à opção de trazer à tona, em sala de aula, a consciência sociopolítica que os aprendizes carregam consigo, rejeitando, dessa forma, a concepção de que o ensino e a aprendizagem de línguas se restringem aos elementos linguísticos e funcionais. Conforme nos lembra Kumaravadivelu $(2001 ; 2006 b)$, esse parâmetro tem inspiração, principalmente, na obra do educador brasileiro Paulo Freire, refletindo também os trabalhos de alguns 
de seus seguidores, entre os quais: Simon (1988), Giroux (1988), Auerbach (1995) e Benesch (2001).

\section{MATERIAL DIDÁTICO VIRTUAL LIVRE COMO PROPOSTA PARA OS CEL}

Em consonância com S0uza (2014), compreendemos, em linhas de síntese, que, para ser considerado de natureza virtual e livre, o material didático deverá ser o fruto de um processo de produção livre, ou seja, processo em que os autores tiveram a liberdade de consumir outros produtos culturais sem a necessidade de permissão de grupos ou corporações que figurem como detentores desses produtos. Esse material, como um bem cultural, deverá, ele próprio, figurar como livre, contribuindo, assim, com a circulação livre da cultura. Em outras palavras, trata-se, como discutimos em Souza (2014), de um tipo de material didático que, em essência, beneficia-se da cultura livre (LESSIG, 2004), ao mesmo tempo em que a promove (SOUZA, 2014), sendo, naturalmente, suscetível à ação da inteligência coletiva, como concebido por Levy (2007).

Consideramos, concordando ainda com Souza (2014), que, para que isso ocorra, esse material didático deverá se inserir em um modelo de negócio livre ou seja, caracterizado pelas liberdades de uso, cópia, modificação, e redistribuição (FREE SOFTWARE FOUNDATION, s.d.; SILVEIRA, 2004), para qualquer um e para qualquer fim (FREE SOFTWARE FOUNDATION, s.d.) - e utilizar como suporte um software, ou, em consonância com Freedomdefined (s.d.), formatos livres. Ele deverá, também, consumir insumos livres e ser, ele próprio, registrado com uma licença livre, sendo o termo licença livre tomado, em ambos os casos, segundo a definição da Freedomdefined (s.d) - ou seja, que, essencialmente, proteja a manutenção das liberdades de uso, cópia, distribuição e modificação (SOUZA, 2014). A FIGURA 1 traz a relação entre a noção de Material Didático Virtual Livre e seus conceitos subjacentes, conforme Souza (2014). 


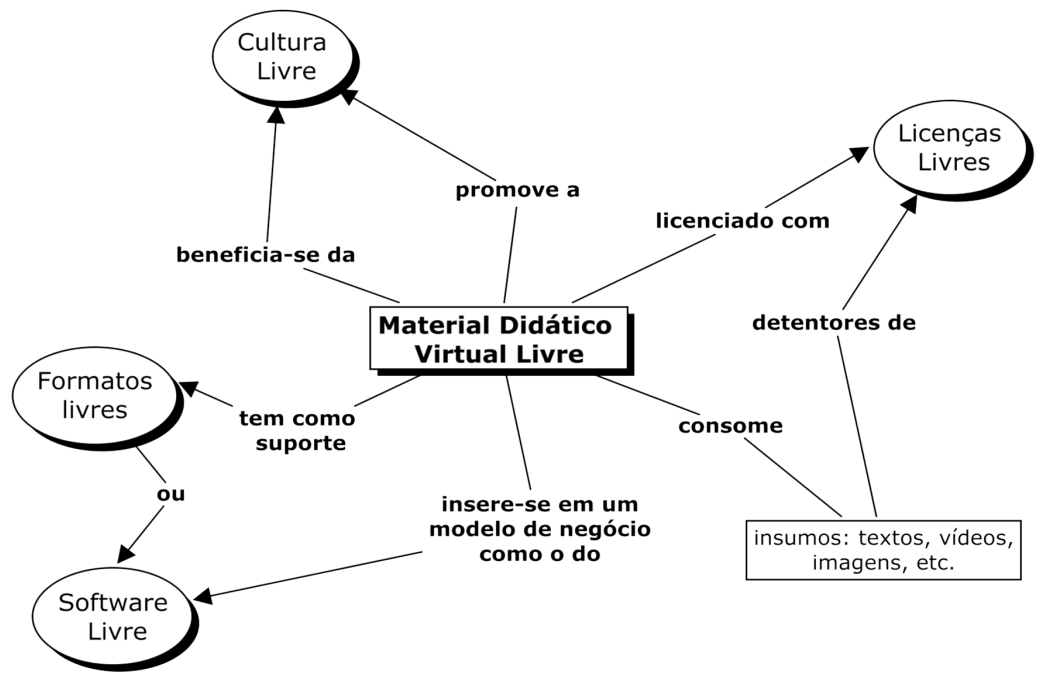

Figura 1. Material Didático Virtual Livre e seus conceitos subjacentes (SOUZA, 2014) Fonte: Souza (2014).

Consideramos que materiais didáticos de natureza virtual livre, em essência, tal qual o software livre, pressupõem a possibilidade de contextualização - ou seja, de personalização sob demandas advindas de contextos de uso; de debate sobre interesses e ideologias implícitas em sua própria gênese - bem como na concepção de materiais didáticos de outras naturezas, como, por exemplo, de materiais didáticos fechados; e de discussão sobre as implicações de sua utilização na vida dos usuários. Isso significa que esse tipo de material didático também pressupõe o empoderamento do professor, oferecendo-lhe níveis mais profundos de apropriação e de personalização - se comparados, por exemplo, com materiais didáticos fechados.

Vale acrescentar que a ideia de Material Didático Virtual Livre poderia ser confundida com a noção de Recursos Educacionais Abertos (REA). Contudo, conforme discutimos em Souza (2014), apesar de muito próximos, os conceitos não são idênticos. De fato, enquanto Recursos Educacionais Abertos podem se referir a qualquer ferramenta ou técnica usada para apoiar o acesso ao conhecimento (tais como: materiais de cursos; módulos; livros-textos; vídeos; provas; software; etc.), Material Didático Virtual Livre se aproxima da ideia geral de sequências didáticas (OLIVEIRA, 2013) materializadas em formato digital. Cabe lembrar que, conforme 
a autora, a ideia de sequências didáticas refere-se a um conjunto de atividades, conectadas entre si, que pressupõem planejamento e que trabalham os conteúdos de forma integrada. Ademais, conforme discutimos em Souza (2014), utilizamos o especificador livre, em detrimento do aberto, uma vez que o consideramos mais condizente com a essência dos construtos teóricos que fundamentam a nossa concepção de Material Didático Virtual Livre: cultura livre (LESSIG, 2004), software livre (FREE SOFTWARE FOUNDATION, s.d.) e licença livre (FREEDOMDEFINED, s.d.).

Conceituados dessa forma, conforme defendemos e discutimos em Souza (2014), os materiais didáticos de natureza virtual livre apresentam características que podem qualificá-los, em essência, como materiais didáticos pós-método, uma vez que também refletem os parâmetros da particularidade, da praticabilidade e da possibilidade, já apresentados neste artigo.

Compreendemos que a utilização de material didático de natureza virtual e livre parece ser a escolha mais adequada para os cursos de língua italiana dos CEL, uma vez que, dada a sua essência condizente com a noção de pedagogia pós-método (KUMARAVADIVELU, 1994), pode corresponder às demandas e tendências apontadas por Peleteiro (2015) e Pinheiro (2013). A esse propósito, veja-se o QUADRO 3.

\section{REPOSITÓRIOS DIGITAIS ONLINE COMO ESPAÇO DE ENSINO, APRENDIZAGEM E (AUTO) FORMAÇÃO CONTINUADA}

Nascimento (2009) caracteriza o repositório digital pela sua função essencial de armazenamento de conteúdo, encontrado por meio de buscas e acessível para reutilização. Nesse sentido, identificação, armazenamento e acesso figuram como aspectos fundamentais desse tipo de construto (NASCIMENTO, 2009). A autora lembra que o nível de acesso pode ser elemento diferenciador entre os diversos tipos de repositórios, variando entre o mais abrangente, o intermediário e o básico (QUADRO 4). O mais abrangente permite que o usuário visualize todo o sistema, inclua e exclua materiais e administre todo o fluxo de informação. O intermediário, por sua vez, permite que o usuário visualize, faça download ou contribua com material. O básico, enfim, permite apenas que o usuário visualize ou visualize e faça download. Reunimos essas características no QUADRO 4. 
Quadro 4. Níveis de acesso de um repositório digital

Nível de acesso

$\begin{array}{ll} & \text { Visualização de todo o sistema. } \\ \text { Inclusão e exclusão de materiais. } \\ \text { Administração de todo o fluxo de informação. }\end{array}$

Intermediário

Básico
Possibilidades para o usuário

Visualização.

Download e contribuição de material.
Apenas visualização.

Apenas visualização e download.

Fonte: adaptado de Nascimento (2009).

Nascimento (2009) aponta, ainda, a interoperabilidade, a possibilidade de colaboração e de sustentabilidade como características desejáveis de um repositório digital. A interoperabilidade permite que o repositório seja utilizado em diferentes sistemas. A possibilidade de colaboração, tal qual um esquema de revisão por pares, pode enriquecer o conteúdo, na medida em que a inteligência coletiva poderá atuar sobre ele, aperfeiçoando-o. A sustentabilidade ou viabilidade está associada à possibilidade de tornar pública a maneira como o repositório armazena e distribui os recursos digitais. Essa característica, como observa a pesquisadora, pode ser acentuada se esses repositórios forem desenvolvidos a partir da filosofia de sistemas de código aberto.

Compreendemos o repositório digital não apenas como um espaço de armazenamento, mas também como lugar de ensino e aprendizagem, tanto para professores, em uma perspectiva de formação ou autoformação continuada, quanto para aprendizes, na ação de aprendizagem ou autoaprendizagem de idiomas.

Considerado o contexto de nossa pesquisa, de fato, uma vez que o repositório digital armazena e disponibiliza sequências didáticas digitais livres (SOUZA, 2014), torna-se lugar de ensino e aprendizagem, já que docentes poderão aprender e ensinar aspectos didáticos, e alunos e alunas poderão aprender idiomas, dentro ou fora dos CEL, nas modalidades de ensino a distância ou híbrida. A preocupação com o design das sequências didáticas, com a metadescrição, com a presença de notas sobre aspectos teórico-pedagógicos e de descrição de contexto de aplicação, entre outros, podem figurar, nesse caso, como elementos-chave, uma vez que poderão 
melhor corresponder a demandas de ensino, de aprendizagem e, sobretudo, de autoaprendizagem.

\section{REPOSITÓRIO DIGITAL ONLINE NO ÂMBITO DOS CEL: MENOS CURRÍCULO, MAIS AUTORIA!}

A Secretaria de Educação do Estado de São Paulo disponibiliza, desde fevereiro de 2014, uma plataforma denominada CURRÍCULO+. Trata-se de um tipo de repositório digital online em que se pretende reunir informações sobre conteúdos digitais (vídeos, videoaulas, jogos, animações, simuladores e infográficos etc.), articulados com o currículo do Estado de São Paulo, visando ao uso complementar em sala de aula (SÃO PAULO, 2014). O CURRÍCULO+ abrange, dessa forma, três níveis de ensino: Ensino Fundamental - anos iniciais $\left(1^{\circ}\right.$ ao $5^{\circ}$ ano); Ensino Fundamental - anos finais $\left(6^{\circ}\right.$ ao $9^{\circ}$ ano); e Ensino Médio.

O conteúdo tem a curadoria de uma equipe composta por professores coordenadores de núcleo pedagógico de diversas diretorias de ensino da rede, representantes de todos os níveis de ensino - a saber: Ensino Médio e anos iniciais e finais do Ensino Fundamental - e docentes responsáveis por disciplinas do currículo, incluindo inglês e espanhol (SÃO PAULO, 2014). Essa equipe se responsabiliza pela seleção das sugestões de conteúdo, as quais podem ser enviadas por educadores da rede, alunos ou outros usuários da plataforma.

O CURRÍCULO+, de fato, não armazena recursos digitais, mas apenas informações e links para acesso a recursos externos. Tomemos, como exemplo, a sugestão de recurso para o ensino de língua espanhola enviado por uma professora da rede, de autoria do Videoele ${ }^{3}$, um portal dedicado ao ensino de espanhol para estrangeiros, intitulado "Donde estás" (FIGURA 2).

3. Disponível em: http://www.videoele.com 


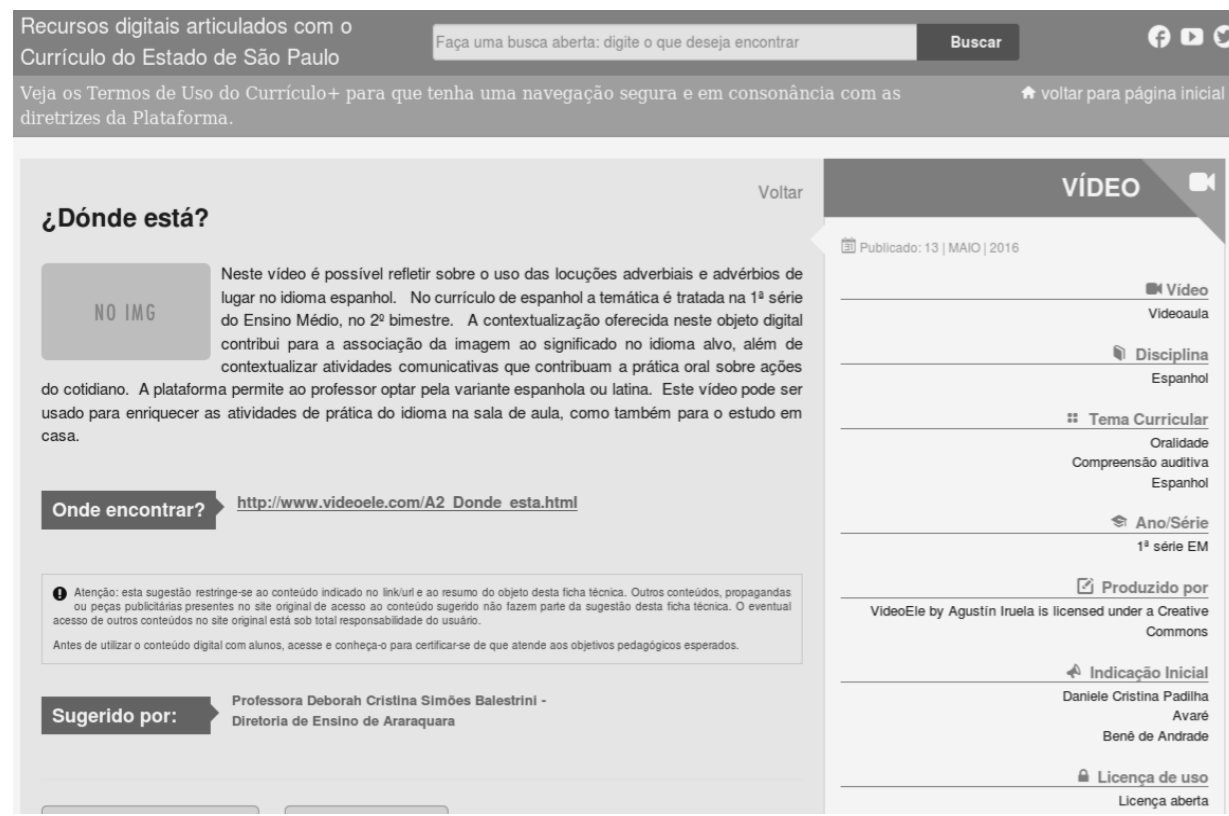

Figura 2. Exemplo de sugestão de recurso digital apresentado no CURRÍCULO+ Fonte: adaptado de São Paulo (2014).

A página em que a sugestão do recurso aparece (FIGURA 2) disponibiliza uma série de informações sobre a atividade. A estrutura de dados que a descreve é padrão para todos os recursos apresentados no CURRÍCULO+. Estão incluídos nesses dados: uma descrição geral do recurso; o tipo de mídia; a disciplina a que se refere; o tema curricular; o ano ou série; a pessoa que indicou; a licença de uso; o idioma; o link de acesso ao recurso; comentários explicativos, por meio dos quais o CURRÍCULO+ recomenda a leitura atenta do conteúdo antes de levá-lo para a sala de aula e se isenta da responsabilidade sobre o conteúdo de terceiros; um sistema de tags, conteúdo relacionado e divulgação do recurso em mídias sociais; e um espaço para comentários, logo abaixo da sugestão, aberto para interação entre os usuários.

Compreendemos que, caracterizado dessa forma, o CURRÍCULO+ não apresenta condições para atender de modo adequado às demandas relativas ao uso e à produção de material didático em uma perspectiva pós-método, ou seja, conforme Souza (2014), ao uso e à produção de material didático de natureza virtual e livre. Trata-se de um repositório centrado no currículo, e não no professor-autor e em suas demandas locais, advindas dos contextos em que atua. 
Sugerimos, por meio do QUADRO 5, um conjunto de aspectos gerais que, do nosso ponto de vista, poderão servir como referência para adaptações ao repositório, de modo a atender tais demandas.

Quadro 5. Sugestão de requisitos para repositórios digitais de material didático de natureza virtual e livre

- $\quad$ Abrigar conteúdo (sequências didáticas; insumos etc.) de autoria dos próprios professores e professoras dos CEL e dos usuários em geral.

- Abrigar conteúdo (sequências didáticas; insumos etc.) de terceiros, desde que licenciados de maneira livre, aberta ou flexível.

- Abrigar obras derivadas (recursos digitais, produzidos a partir de outros recursos).

- Restringir-se ao uso de insumos (texto, imagem, vídeo etc.) com licenças livres ou flexíveis.

- Prover recursos automatizados de: identificação de autoria identificação de usuários identificação de licenças; identificação e correlação de trabalhos derivados; busca especializada.

- Inserir campos para a descrição dos contextos para os quais os recursos sugeridos foram elaborados. Associar as descrições de contexto ao recursos, em todos os âmbitos do sistema.

- Caracterizar-se como um repositório abrangente, ou seja, que permita: visualização de todo o sistema; inclusão e exclusão de materiais; administração de todo o fluxo de informação (NASCIMENTO, 2009).

- $\quad$ Promover a interoperabilidade e prezar por ela.

- Incluir e disponibilizar metadados.

- Potencializar a possibilidade de colaboração e de sustentabilidade.

- Optar por formatos e padrões abertos.

- Optar pelo uso de software livre.

- Tornar pública a maneira como o repositório armazena e distribui os recursos digitais.

Consideramos que os aspectos que reunimos no QUADRO 5 podem figurar, ainda, como requisitos (PAULA-FILHO, 2003) gerais a serem considerados para a criação ou adaptação de qualquer outro repositório digital que tenha como alvo o trabalho com materiais didáticos de natureza virtual e livre .

Entendemos, enfim, que os repositórios digitais online que, de algum modo, reflitam esses aspectos poderão melhor corresponder às demandas dos CEL, uma vez que, conforme defendemos neste artigo e na fundamentação de nossa pesquisa, consideramos materiais didáticos de natureza virtual e livre a proposta mais adequada para esse contexto de ensino e aprendizagem de idiomas. 


\section{0 DESIGN DE MATERIAL DIDÁTICO NA PERSPECTIVA DA PEDAGOGIA PÓS- MÉTODO: DESIGN BASEADO EM PRINCÍPIOS}

Conforme discutimos, Kumaravadivelu (2006b) defende o estabelecimento de alternativas ao método, em detrimento da busca de métodos alternativos, no âmbito do ensino de idiomas. Ele sugere como alternativa a adoção de quadros de referência, coerentes e compreensíveis, compatíveis com o estado atual do conhecimento, neutros com relação aos métodos, mas não desconectados de teorias, que possam guiar os professores em sua prática. $\mathrm{O}$ autor cita, pelo menos, três quadros: o Quadro Referencial Tridimensional de Stern, o Quadro de Referência Prático Exploratório de Allwright e o seu próprio Quadro Referencial de Macroestratégias.

Da mesma forma, compreendemos a produção de material didático na perspectiva da pedagogia pós-método como uma atividade embasada em princípios, ou quadros de referência - coerentes, compreensíveis, compatíveis com o estado atual do conhecimento e neutros em relação a métodos -, uma vez que consiste em uma atividade essencial da prática docente. Trata-se de uma prática que também reflete, de algum modo, os parâmetros da particularidade, da praticabilidade e da possibilidade.

Desse modo, será constante a preocupação com: o reconhecimento e a compreensão das demandas e das particularidades linguísticas, socioculturais e políticas do contexto local de aplicação do material didático; a autonomia didáticoteórica do professor enquanto autor do seu material didático, desvencilhando-se de um modelo dicotômico, típico da noção de métodos, em que se insere como mero consumidor e executor de materiais didáticos elaborados por teóricos, em uma perspectiva prescritiva e descendente (top-down); uma sensibilidade crítica que permita trazer à tona a consciência sociopolítica que os aprendizes carregam enquanto indivíduos viventes em diversas esferas sociais, negando, dessa forma, a concepção de que o ensino de línguas se restringe a elementos linguísticos e funcionais.

Vale ressaltar que compreendemos a utilização de materiais didáticos de terceiros (de colegas, por exemplo) como prática comum e desejável no ensino e aprendizagem de idiomas e, também, no contexto da pedagogia pós-método ou na utilização de materiais didáticos de natureza virtual e livre. Entendemos, no entanto, que tal prática é fruto de compartilhamento, de cooperação e da ação da inteligência coletiva, constituindo-se em uma prática que conota horizontalidade entre os professores-autores de material didático. Tal prática diferencia-se, portanto, da ideia de uma relação vertical, imposta, prescritiva, descendente (top- 
down), relacionada ao já citado modelo dicotômico, típico da noção de métodos, em que se opõe o professor ao teórico. A utilização de material didático de terceiros, nesse sentido, pressupõe avaliação e pode envolver ou não adaptações.

Encontramos perspectiva análoga à de Kumaravadivelu (2006b) em Tomlinson $(2010 ; 2016)$. O autor defende a produção de material didático orientada por princípios, os quais seriam, por sua vez, estabelecidos a partir de pesquisas em aquisição de segunda língua e em sala de aula, que sejam coerentes com a experiência prática dos professores- autores de materiais didáticos. Tomlinson (2016) lembra que, nem sempre, a literatura sobre aquisição demonstra um acordo sobre os seus temas, mas ressalta que há, sim, aspectos de consenso, nos quais o autor ou autora de material didático de idiomas pode se embasar, uma vez que considere coerente com a sua prática e com a sua percepção sobre fatores que podem contribuir para aquisição.

Reunimos, no QUADRO 6, a título de exemplo, os princípios que compõem o Quadro Referencial de Macroestratégias, de Kumaravadivelu (2006b), e os princípios que, segundo Tomlinson (2016), representam uma série de pré-requisitos que parecem colaborar para o sucesso da aquisição de uma segunda língua.

Quadro 6. Quadro Referencial de Macroestratégias (KUMARAVADIVELU, 2006b) e prérequisitos para aquisição (TOMLINSON, 2016)

\begin{tabular}{|c|c|}
\hline $\begin{array}{l}\text { Quadro Referencial de Macroestratégias } \\
\text { (Kumaravadivelu, 2006b) }\end{array}$ & $\begin{array}{l}\text { Pré-requisitos para aquisição } \\
\quad \text { (Tomlinson, 2016) }\end{array}$ \\
\hline $\begin{array}{l}\text { - Maximize as oportunidades de } \\
\text { - } \quad \text { Facilite a interação negociada. } \\
\text { - } \quad \text { Minimize os problemas de } \\
\text { intercompreensão entre professor e } \\
\text { aluno. } \\
\text { - } \text { Ative a intuição dos aprendizes sobre } \\
\text { - } \quad \text { Promova da percepção sobre a língua. } \\
\text { - } \quad \text { Contextualize o insumo linguístico. } \\
\text { - } \quad \text { Integre as habilidades. } \\
\text { - } \quad \text { Promova a autonomia do aprendiz. } \\
\text { - } \text { Aumente a consciência cultural. } \\
\text { - Garanta a relevância social. }\end{array}$ & $\begin{array}{l}\text { - Os aprendizes são expostos a insumo } \\
\text { rico, recorrente, significativo e } \\
\text { compreensível de língua em uso? } \\
\text { - Os aprendizes são envolvidos } \\
\text { emocionalmente? } \\
\text { - Os aprendizes estão envolvidos } \\
\text { cognitivamente? } \\
\text { Os aprendizes são, eventualmente, } \\
\text { orientados a focalizar a atenção } \\
\text { na forma enquanto ou depois que } \\
\text { focalizam o sentido? } \\
\text { Os aprendizes têm farta oportunidade } \\
\text { de usar a língua para comunicação? }\end{array}$ \\
\hline
\end{tabular}

Fonte: adaptado de Kumaravadivelu (2006b) e Tomlinsom (2016) ${ }^{4}$.

4. Tradução nossa (QUADRO 6; QUADRO 7; e QUADRO 8, quando pertinente). 
Tomlinson (2010), além dos pré-requisitos ou princípios que considera fundamentais para o sucesso da aquisição, sugere uma lista de princípios relacionados à perspectiva do ensino, chamando-os de "princípios de ensino de línguas" (TOMLINSON, 2010, p. 94). Reunimos esses princípios, a título de exemplo, no QUADRO 7.

Quadro 7. Princípios de ensino de línguas (TOMLINSOM, 2010)

- O conteúdo e a metodologia do professor devem ser consistentes com os objetivos do curso e devem coincidir com as demandas e as preferências dos aprendizes.

- $\quad$ O ensino deve ser elaborado com o objetivo de auxiliar os aprendizes a desenvolver competências relacionadas ao uso da língua.

- O ensino deve ser elaborado com o intuito de oferecer oportunidades de aprendizagem que ajudarão no desenvolvimento educacional dos aprendizes, incentivando-os a se tornarem mais maduros, mais críticos, mais criativos, mais construtivos, mais colaborativos, mais capazes e mais confiantes.

- O professor deve ser capaz de personalizar os materiais didáticos de modo a torná-los mais coerentes com as diversas necessidades, preferências e estilos de aprendizagem dos aprendizes

Fonte: adaptado de Tomlinson (2010).

Nenhum dos quadros que apresentamos (QUADRO 6, QUADRO 7 e QUADRO 8) tem caráter prescritivo, configurando-se como um conjunto de princípios derivados de conhecimento teórico, empírico e pedagógico, relacionado ao ensino e à aprendizagem de idiomas.

Em termos de aplicação dos princípios, enquanto Kumaravadivelu (2006b) defende a ideia de microestratégias, ou seja, procedimentos de sala de aula, elaborados para "realizar os objetivos de uma macroestratégia específica" (KUMARAVADIVELU, 2006b, p. 208), considerando-se as demandas locais de ensino e aprendizagem, Tomlinson (2010) propõe a elaboração de princípios e procedimentos de desenvolvimento de materiais didáticos a partir dos prérequisitos ou princípios de aquisição.

Exemplificamos, por meio do QUADRO 8, as relações entre os princípios de aquisição de língua, os princípios de ensino de línguas e os princípios de produção de material didático, conforme proposta de Tomlinson $(2010,2016)$, bem como a relação entre macro e microestratégias, conforme proposta de Kumaravadivelu (2006b). Eventualmente, inserimos, também no QUADRO 8, sugestões de princípios de nossa autoria. Essa ação deflagra a natureza não prescritiva, dinâmica e autoral da elaboração de princípios visando ao apoio à prática docente e, em 
especial, conforme focalizamos neste trabalho, à produção de material didático de idiomas em uma perspectiva pós-método.

Quadro 8. As relações entre categorias de princípios e entre as macro e microestratégias

\begin{tabular}{|c|c|}
\hline & Princípio de produção de material didático (decorrente) \\
\hline $\begin{array}{l}\text { Princípio de aquisição de língua: } \\
\text { Aprendizes podem } \\
\text { se beneficiar quando } \\
\text { percebem aspectos salientes } \\
\text { do insumo (TOMLINSON, } \\
\text { 2010). }\end{array}$ & $\begin{array}{l}\text { - Adote uma abordagem experiencial (KOLB, } \\
\text { 1984) em que os aprendizes são, antes de } \\
\text { tudo, envolvidos holisticamente. No primeiro } \\
\text { momento, os aprendizes aprendem de modo } \\
\text { implícito, sem focalizar nenhum aspecto } \\
\text { particular da experiência (ex.: responder } \\
\text { perguntas sobre um texto). Mais tarde, revisitam } \\
\text { a experiência, e sua atenção volta-se para } \\
\text { aspectos particulares de modo a experienciar } \\
\text { uma aprendizagem explícita (ex.: observar } \\
\text { aspectos específicos do texto). (adaptado de } \\
\text { TOMLINSON, 2010). } \\
\text { Em vez de chamar a atenção dos aprendizes para } \\
\text { um aspecto particular de um texto e, em seguida, } \\
\text { fornecer-lhes informações explícitas sobre o seu } \\
\text { uso, é mais eficiente auxiliá-los a descobrir as } \\
\text { características (preferencialmente, de modo } \\
\text { colaborativo) por si próprios (TOMLINSON, } \\
\text { 2010). }\end{array}$ \\
\hline 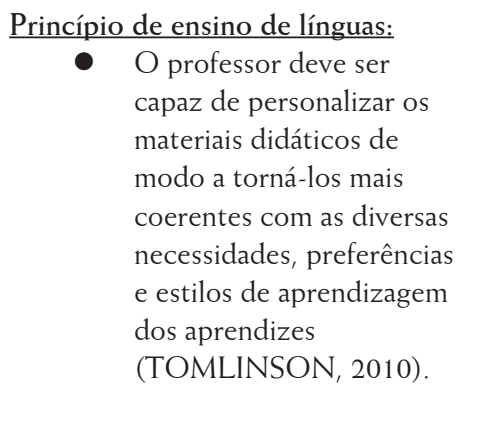 & $\begin{array}{l}\text { - Os materiais didáticos devem possibilitar novas } \\
\text { ideias ao professor (às vezes, por meio de bancos } \\
\text { de atividades) com o intuito de personalizar } \\
\text { atividades genéricas (TOMLINSON, 2010). } \\
\text { Os materiais didáticos devem auxiliar o } \\
\text { professor a sugerir caminhos por meio dos } \\
\text { quais os aprendizes possam fazer suas escolhas } \\
\text { individuais, trabalhando em seu próprio nível e } \\
\text { ritmo (TOMLINSON, 2010). } \\
\text { Os materiais didáticos devem ser de natureza } \\
\text { personalizável (SUGESTÃO NOSSA). }\end{array}$ \\
\hline & Microestratégia \\
\hline
\end{tabular}




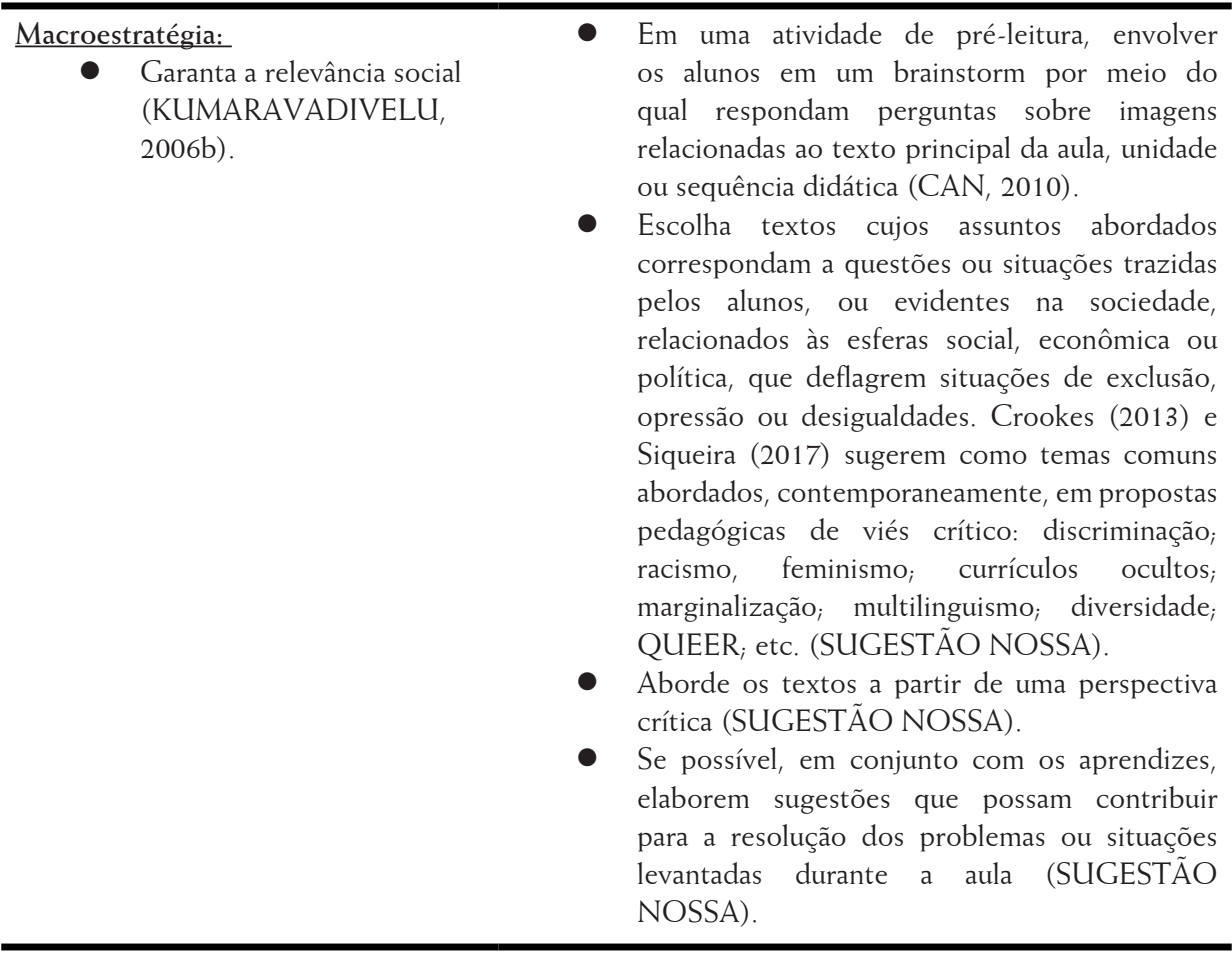

O princípio de produção de material didático que sugerimos no QUADRO 8 - a saber: "os materiais didáticos devem ser de natureza personalizável" - está embasado em SOUZA (2014). As microestratégias, que também sugerimos no QUADRO 8, com o intuito de corresponder à macroestratégia "garanta a relevância social" (KUMARAVADIVELU, 2006b), estão diretamente relacionadas ao parâmetro da possibilidade e refletem aspectos da pedagogia crítica, conforme Rajagopalan (2003), Pennycook (2001), Maclaren (1997), Crookes (2013) e Siqueira $(2013,2017)$. Nesse sentido, concordamos com Crookes (2013), quando defende que o fazer pedagógico crítico significa:

[...] ensinar para justiça social, de modo a favorecer o desenvolvimento de cidadãos ativos e engajados que irão, conforme as circunstâncias permitirem, questionar de modo crítico o motivo pelo qual as vidas de muitos seres humanos, talvez incluindo as próprias vidas, são materialmente, psicologicamente, socialmente e espiritualmente inadequadas [...] cidadãos que serão preparados para procurar soluções para os problemas que enfrentam, ou com os quais se deparam, e tomar ações de acordo com tais problemas. (CROOKES, 2013, p. 8)

Apresentamos, no APÊNDICE A, três propostas de atividades interconectadas, por meio das quais ilustramos a aplicação das microestratégias 
que apresentamos no QUADRO 8. Ressaltamos que, conforme Kumaravadivelu (2006b), cada macroestratégia pode contar com infinitas possibilidades e tipos de microestratégias, ou seja, consequentemente, infinitas possibilidades de design. Essas possibilidades, ainda segundo o autor, poderão ser limitadas pelos fatores que delineiam e orientam o contexto local de ensino e aprendizagem que se inserem, tais como as políticas linguísticas - nas esferas locais, regionais ou nacionais -, os objetivos do currículo, entre outros (KUMARAVADIVELU, 2006). Naturalmente, as microestratégias serão elaboradas considerando-se tanto as demandas dos aprendizes quanto o nível de conhecimento sobre a língua.

Compreendemos - concluindo esta seção - que, em linhas de síntese, a produção de material didático em uma perspectiva pós-método envolve a elaboração ou escolha de princípios por parte dos professores-autores de material didático, com o objetivo de informar-se e de embasar escolhas de design do material didático. Referimo-nos, por exemplo, entre outros fatores, à escolha do insumo, dos tipos de atividades, das tecnologias, dos suportes ou, ainda, das estratégias de ensino e aprendizagem a serem representadas em seu material.

\section{CONCLUSÕES}

Trouxemos, neste artigo, os aspectos essenciais e os resultados parciais de nossa pesquisa de pós-doutorado. Os resultados são fruto de nossos esforços para melhor compreender o contexto dos Centros de Estudos de Línguas (CEL) do Estado de São Paulo, considerando, especialmente, a possibilidade de implementação da pesquisa e da utilização de Material Didático Virtual Livre nesse contexto.

No decorrer do artigo, discutimos a problemática do material didático no contexto dos cursos de italiano dos CEL, deflagrando, com base em Peleteiro (2015) e Pinheiro (2013), a sua vocação para a utilização de materiais didáticos essencialmente personalizados e personalizáveis. Frente a essa questão, caracterizamos materiais didáticos de natureza virtual e livre, discutindo a sua correlação com a pedagogia pós-método, conforme Souza (2014), e propusemos esse tipo de material didático como o mais adequado para o contexto dos CEL, uma vez que são, essencialmente, de natureza personalizável. Trata-se da nossa principal hipótese de trabalho.

Apontamos e sugerimos requisitos para o design de repositórios virtuais que consideramos adequados para o desenvolvimento e a utilização de materiais didáticos de natureza virtual e livre. Nossas sugestões foram elaboradas a partir da análise do CURRÍCULO+, repositório digital da Secretaria de Educação do 
Estado de São Paulo, que consideramos inadequado às demandas relativas ao uso e à produção de materiais didáticos em uma perspectiva pós-método, ou seja, ao uso e à produção de materiais didáticos de natureza virtual e livre (SOUZA, 2014). A inadequação consiste, principalmente, por se tratar de um repositório centrado no currículo, e não no professor-autor e em suas demandas locais, advindas dos contextos em que atua.

Discorremos, enfim, sobre a metodologia de produção de material didático na perspectiva da pedagogia pós-médodo, que experimentamos e buscamos aprimorar em nossa pesquisa. Defendemos que a produção de material didático na perspectiva da pedagogia pós-método envolve o estabelecimento e a utilização de princípios, ou quadros de referência, compatíveis com o estado atual do conhecimento, coerentes, compreensíveis, neutros em relação a métodos e de caráter não prescritivo. Fundamentamo-nos em Kumaravadivelu (2006b) e em Tomlinson $(2010 ; 2016)$. Trata-se, ademais, de uma prática que também reflete, de algum modo, os parâmetros da particularidade, da praticabilidade e da possibilidade.

\section{$\overline{\text { REFERÊNCIAS }}$}

ABED. Repositórios e Referatórios de Objetos de Aprendizagem e Outros Recursos Educacionais. Disponível em: http://www2.abed.org.br/documentos/Arquivo Documento609.pdf Acesso em: 20 ago. 2016.

AUERBACH, E. R. (1995). The politics of the ESL classroom: Issues of power in pedagogical choices. In: Tol-Lefson, J. W. (ed.), Power and inequality in language education. [S.I.]: Cambridge University Press, pp. 9-33.

BENESCH, S. (2001). Critical English for Academic Purposes: Theory, Politics, and Practice. Taylor \& Francis.

CALLEGARI, M. O. V. (2008). Motivação, ensino e aprendizagem de espanhol: caminhos possíveis. Análise e intervenção num centro de estudos de línguas de São Paulo. Tese de Doutorado em Educação. Faculdade de Educação, Universidade de São Paulo, São Paulo. Doi:10.11606/T.48.2008.tde-18032009-154414. Acesso em: 16 fev. 2016.

CAN, N. (2008). Post-Method Pedagogy: Teacher Growth behind Walls. Proceedings of the 10th METU ELT Convention. 
ROCHA, V. G. (2016). Estratégias de ensino nas salas multisseriadas de italiano dos Centros de Estudos de Línguas (CELs) da capital e da grande São Paulo. Tese de Doutorado em Língua e Literatura Italiana. Faculdade de Filosofia, Letras e Ciências Humanas, Universidade de São Paulo, São Paulo.

CROOKES, G. (2013). Critical ELT in action: Foundations, promises, praxis. New York: Routledge.

DIADORI, P. (2001). Insegnare italiano a stranieri. Itália: Le Monnier.

FREEDOMDEFINED. (s.d). Trabalhos Culturais Livres. Disponível em: http:// freedomdefined.org._Acesso em: 20 mai. 2014.

FREE SOFTWARE FOUNDATION. (s.d). Disponível em: https://www.fsf.org/. Acesso em: 20 mai. 2014.

GASPARELO, L. de F. (2009). O Centro de Estudos de Línguas de Sorocaba: projeto pedagógico e prática de ensino. Dissertação de Mestrado em Educação. Programa de Pós-graduação em Educação, Universidade de Sorocaba, Sorocaba.

GIROUX, H. (1988). Teachers as Intellectuals: Toward a Critical Pedagogy of Learning. Bergin \& Garvey.

KOLB, D. (1984). Experiential learning: experience as the source of learning and development. Englewood Cliffs, New Jersey: Prencice Hall.

KUMARAVADIVELU, B. (1994). The postmethod condition: (e)merging strategies for second/foreign language teaching. TESOL Quarterly. v. 28, $\mathrm{n}^{\circ} 1$, pp. 27-48.

KUMARAVADIVELU, B. (2001). Toward a Postmethod Pedagogy. TESOL Quarterly, Teachers of English to Speakers of Other Languages. v. 35, n 4, pp. 537-560.

KUMARAVADIVELU， B. (2003). Beyond Methods: Macrostrategies for Language Teaching. New Haven: Yale University Press.

KUMARAVADIVELU, B. (2006a). TESOL Methods: Changing Tracks, Challenging Trends. TESOL Quarterly, Teachers of English to Speakers of Other Languages. v. $40, n^{\circ} 1$, pp. 59-81.

KUMARAVADIVELU, B. (2006b). Understanding Language Teaching: From Method to Post-method. New Jersey: Lawrence Erlbaum Associates. 
LESSIG, L. (2004). Free Culture: The Nature and Future of Creativity. United States of America: Penguin Group.

LEVY, P. (2007). Inteligência coletiva. São Paulo: Edições Loyola.

McLAREN, P. (1997). Critical Pedagogy. Teaching Education Journal. v. 9, nº 1, pp. 1-1.

NASCIMENTO, A. C. A. de A. (2009). Aprendizagem por meio de Repositórios Digitais, Virtuais. In: Litto, F. M, Formiga, M. (orgs.), Educação a Distância: o estado da arte. São Paulo: Pearson, pp. 352-357.

OliveIRA, M. (2013). Sequência Didática Interativa no Processo de Formação de professores. Petrópolis: Editora Vozes.

ORTALE, F. L. (2010). O ofício de formar professores de línguas: dilemas e possibilidades de atuação. In: I CIPLOM - Congresso Internacional de Professores de Línguas Oficiais do Mercosul. Anais. São Paulo: Apeesp - Associação de Professores de Espanhol do Estado de São Paulo, pp. 421-428. Disponível em: http://www.apeesp. com.br/web/ciplom/Arquivos/artigos/pdf/fernanda-ortale.pdf Acesso em: 20 jan. 2015 .

ORTALE, F. L. (2011). Os Problemas de Ensino como instrumento na formação de professores de italiano. Revista de Italianística. v. 21, n²2, pp. 81-92.

ORTALE, F. L.; ZORZAN, F. J. de A. (2013). Mapeamento dos Municípios com Ensino de Italiano em Escolas Públicas. Revista de Italianística. v. 26, pp. 121-144.

PAULA FILHO, W. P. (2003). Engenharia de Software: fundamentos, métodos e padrões. Rio de Janeiro: Editora LTC.

PELETEIRO, A. C. (2016). O italiano nos Centros de Estudo de Línguas (CEL): funcionamento e análise do material didático em elaboração. Dissertação de Mestrado em Língua e Literatura Italiana. Faculdade de Filosofia, Letras e Ciências Humanas, Universidade de São Paulo, São Paulo. Disponível em: http://www.teses. usp.br/teses/disponiveis/8/8148/tde-29082016-112913/ Acesso em: 07 jun. 2017.

PENNYCOOK, A. (2001). Critical Applied Linguistics: An introduction. Mahwah, New Jersey/London: Lawrence Erlbaum Associates Publishers.

PINHEIRO, A. (2013). Projeto de elaboração de material didático para o curso de Língua Italiana do C.E.L. (Centro de Estudos de Línguas): Italiano in foco. São Paulo. Não publicado. 
RAJAGOPALAN, K. (2003). Por uma linguística crítica: Linguagem, identidade e a questão ética. São Paulo: Parábola Editorial.

ROCHA, V. G. (2016). Estratégias de ensino nas salas multisseriadas de italiano dos Centros de Estudos de Línguas (CELs) da capital e da grande São Paulo. Tese de Doutorado em Língua e Literatura Italiana. Faculdade de Filosofia, Letras e Ciências Humanas, Universidade de São Paulo, São Paulo. Disponível em: http://www.teses. usp.br/teses/disponiveis/8/8148/tde-06122016-120945/. Acesso em: 16 fev. 2017.

SANTOS, J. J. dos. (2011). Dimensões da qualidade educativa nos Centros de Estudos de Línguas do estado de São Paulo (CEL-SP): subsídios à implementação do ensino de espanhol nas escolas públicas paulistas. Dissertação de Mestrado em Educação. Faculdade de Educação, Universidade de São Paulo, São Paulo.

SÃO PAULO (Estado). (1987). Decreto Estadual n ${ }^{\circ} 27.270$, de 10 de agosto de 1987. Dispõe sobre a criação dos Centros de Estudos de Línguas no âmbito da Rede Estadual de Ensino de São Paulo. Disponível em: http://www.al.sp.gov.br/repositorio/legislacao/ decreto/1987/decreto-27270-10.08.1987.html. Acesso em: 16 abr. 2017.

SÃO PAULO (Estado). (1988). Resolução SE n¹93, de 18 de agosto de 1988. Dá nova redação ao parágrafo único do artigo $1^{\circ}$ da Resolução SE271/87. Disponível em: http://siau.edunet.sp.gov.br/ItemLise/arquivos/notas/193_1988.HTM. Acesso em: 16 abr. 2017.

SÃO PAULO (Estado). (2014). Secretaria de Educação. Curriculo+: recursos digitais articulados com o currículo do Estado de São Paulo. Disponível em: curriculomais. educacao.sp.gov.br. Acesso em: 20 fev. 2017.

SÃO PAULO (Estado). (2016a). Secretaria de Educação. Programa da Educação proporciona ensino de até sete idiomas para alunos do Ensino Fundamental e Ensino Médio. Disponível em: http://www.educacao.sp.gov.br/centro-estudo-linguas. Acesso em: 25 ago. 2016.

SÃO PAULO (Estado). (2016b). Secretaria de Educação. Estudantes da rede pública podem se inscrever para cursos gratuitos de idiomas. Disponível em: http://www. educacao.sp.gov.br/noticias/estudantes-da-rede-publica-podem-se-inscrever-paracursos-gratuitos-de-idiomas. Acesso em: 25 ago. 2016.

SÃO PAULO (Estado). (2016c). Secretaria de Educação. Publicação on-line [mensagem pessoal]. Mensagem recebida por romulosouza@usp.brem 07 dez. 2016. 
SILVEIRA, S. (2004). Software livre: a luta pela liberdade do conhecimento. São Paulo: Editora Fundação Perseu Abramo.

SIMON, R. I. (1988). For a pedagogy of possibility. In: Smyth, J. (ed.), The critical pedagogy networker. Victoria, Australia: Deakin University Press, v. I, pp. 1-4.

SIQUEIRA, S. (2013). English as a Lingua Franca: For a Critical Intercultural Pedagogy. In: Lapriore, L.; Grazzi, E. Intercultural Communication. New Perspectives from ELF. Roma: RomaTrE-Press, pp. 189-209.

SIQUEIRA, S. (2017). English for the real world: sharing ideas and possibilities of Critical Pedagogy oriented materials. Jornada Internacional de Línguística Aplicada Crítica (JILAC). Minicurso. Brasília.

SOUZA, Rômulo Francisco de. (2014). Implicações do uso de Material Didático Virtual Livre em contexto formal de ensino-aprendizagem de italiano como LE/L2: a perspectiva dos Problemas de Ensino. Tese (Doutorado em Língua e Literatura Italiana) - Faculdade de Filosofia, Letras e Ciências Humanas, Universidade de São Paulo, São Paulo.

SOUZA, Rômulo Francisco de. (2016). A Formação de Professores de Idiomas na Era Pós-método - A Perspectiva dos Problemas de Ensino. In: NETTO, Tania Maria de Castro de Carvalho; PRAXEDES, Carmem. Licenciatura sem fronteiras: semiosferas em transformação. Rio de Janeiro: EdUERJ.

SOUZA, Rômulo Francisco de. (2017). Métodos, instrumentos e perspectivas teóricas da pesquisa em Problemas de Ensino - dos relatos dos professores à Teoria Fundamentada. In: ORTALE, Fernanda Landucci; FERRONI, Roberta. Luz, Câmera e Ação! O Professor-autor da sala de línguas estrangeira. São Paulo: Humanitas.

TOMLINSON, B. (1998). Introduction. In: Tomlinson, B. (org.), Materials development in language teaching. Cambridge: Cambridge University Press, pp. 1-24.

TOMLINSON, B. (2003). Materials Development Courses. In: Tomlinson, B. Developing materials for language teaching. Londres: Continuum Books, pp. 445-461.

TOMLINSON, B. (2010). Principles of effective materials development. In: Richards, J. (org.), English language teaching materials: theory and practice. New York: Cambridge University Press, pp. 81-108. 
TOMLINSON, B. (2016). Achieving a match between SLA theory and materials development. In: Tomlinson, B. (org.), SLA Research and materials development for language learning. New York: Routledge, pp. 3-22. 


\section{APÊNDICE A - ATIVIDADES QUE ILUSTRAM AS MICROESTRATÉGIAS RELATIVAS À MACROESTRATÉGIA "GARANTA A RELEVÂNCIA SOCIAL"}

\section{Le parole uccidono}

Atividade de Pré-leitura: os aprendizes são convidados a um exercício de brainstorm, tendo elemento motivador as imagens abaixo. O professor ou professora expõe as imagens e escreve, no quadro, as opiniões dos aprendizes sobre as imagens. $\mathrm{O}$ debate pode ser na língua-alvo ou na língua materna. Pode ser um bom momento para introduzir vocabulário sobre o tema - o qual se encontra também no texto principal - antecipando-o, portanto.

Questões para motivar a atividade: $\mathrm{O}$ que você acha das imagens abaixo? Qual situação elas deflagram? Você já viu ou já foi vítima de discurso de ódio? Geralmente, quais são os alvos de discurso de ódio na internet? Você acha que a internet é a causa do discurso de ódio? O que você acha que pode ser feito no sentido de inibir o discurso de ódio?

\section{LE PAROLE UCCIDONO. P R I S M

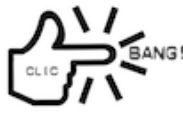 \\ WORDS ARE WEAPONS.

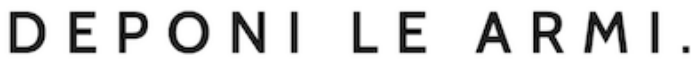

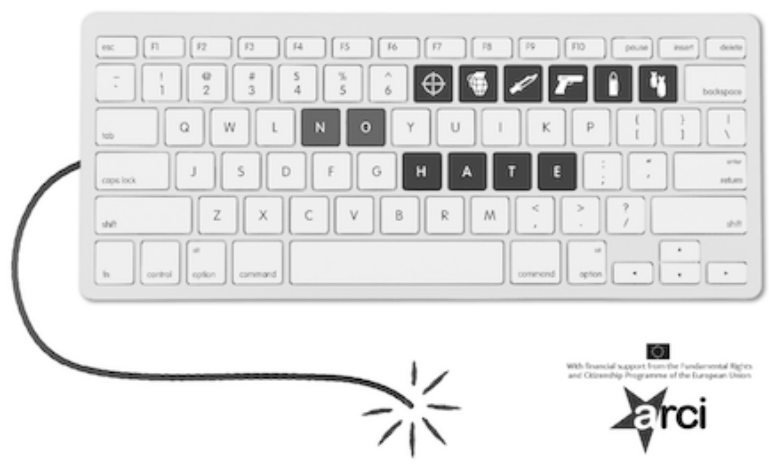

Arci: No all'odio. No all'intolleranza sul web www.arcilombardia.it 


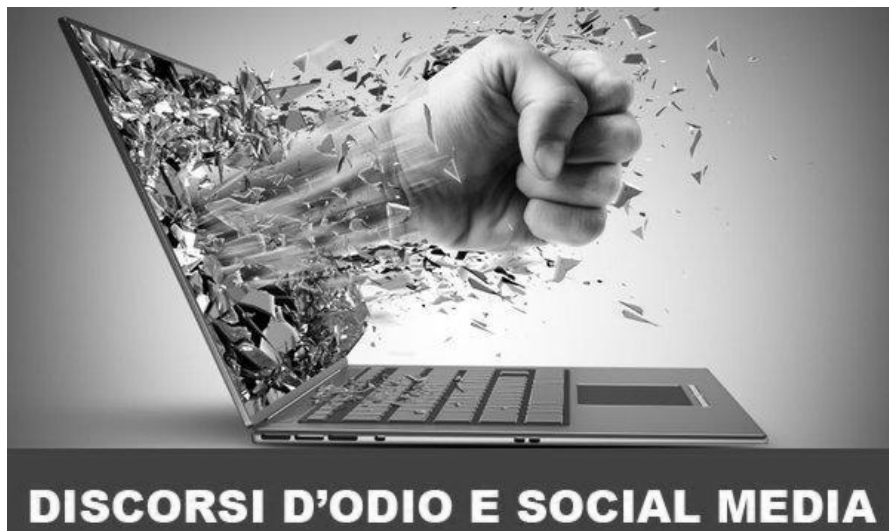

Piattaforma delle resistenze contemporanee

http://www.piattaformaresistenze.it

Atividade de Leitura: o professor ou professora disponibiliza o texto aos aprendizes e lhes pede para responder as questões subsequentes. Solicita-lhes que discutam as respectivas respostas em duplas e, em seguida, abre o debate para toda a turma. O debate pode ser feito em língua materna ou na língua-alvo, de acordo com o perfil do grupo ou com os objetivos do curso.

\section{Hate speech, tecniche educative e di controllo del fenomeno} Angela Caporale

Le parole contano. Sono leggere quando lodano, sono macigni quando insultano. Contano al punto che da alcune frasi possono nascere litigi, contrasti, crimini. Per questo parlare di bate speech, "discorso d'odio", oggi deve essere una priorità. Frasi e strali che incitano alla discriminazione e all'intolleranza su base razziale, religiosa, sessuale, di genere sono all'ordine del giorno, in netta crescita a partire dal 2014 quando l'UNAR, l'Ufficio nazionale anti-discriminazioni razziali, ha iniziato a registrarne i casi online. Nel primo anno, infatti, sono stati segnalati 270 commenti contenenti espressioni razziste sui social network e sui media. In concomitanza con la "crisi dei rifugiati" il fenomeno è cresciuto a livello europeo, al punto che è stato possibile individuare alcune caratteristiche trasversali di chi tende a commentare e diffondere messaggi d'odio. (...)

Il rapporto \#SilenceHate, redatto nell'ambito del progetto BRICkS Against Hate Speech, evidenzia come non vi siano argomenti "sicuri". Ogni tema può essere oggetto di commenti d'odio, ma quelli che sembrano stimolarlo 
maggiormente sono gli articoli o i post che toccano l'emotività e i casi di violenza. Gli strali dell'bate speech sono, generalmente, diretti nei confronti di migranti, stranieri, donne e omosessuali. Il soggetto che esterna il proprio odio online può essere uomo o donna, vivere in qualsiasi Regione d'Italia, ma il sentimento prevalente è la rassegnazione, la rabbia o l'aggressività. (...)

Ciò che emerge dalla ricerca condotta da Sgw proprio sull'bate speech è che il $58 \%$ degli intervistati ritiene che si tratti di un fenomeno diffuso e pervasivo in Rete, ma la tendenza è a bollare l'hater come un "leone da tastiera" con cui non vale la pena interloquire. Tuttavia, come ben sottolinea su Paginag9 Massimo Mantellini, non è Internet a farci odiare.

L'ambiente mediale online replica dinamiche e rapporti di forza reali: "L'odio che osserviamo non è quello dei cosiddetti 'leoni da tastiera', strani esseri antropomorfi degni del Manuale di Zoologia Fantastica di Borges, ma il nostro, quello banale delle nostre carte di identità. Quello della nostra poca cultura, dei libri che non leggiamo, della modesta classe dirigente che riusciamo a produrre. Il linguaggio di Matteo Salvini o quello di Beppe Grillo sono il nostro linguaggio, al quale, forse, un brillante comunicatore web ba aggiunto il cinismo necessario per renderlo più incisivo."

Ecco allora che emerge, da un lato, quella che gli anglosassoni chiamano digital literacy, ovvero l'educazione al mondo digitale che dovrebbe partire già dalle scuole, dall'altro la necessità di agire concretamente per arginare l'bate speech. Come sottolineato nuovamente dal rapporto di BRICkS against hate speech, un ruolo fondamentale è quello svolto dalla moderazione dei commenti. Social media manager e giornalisti, in questo senso, possono arginare il dilagare di discorsi d'odio e interagire con gli haters.

Adattato da: vociglobali.it

\section{Questões sobre o texto:}

1) Você concorda com a frase "Le parole contano. Sono leggere quando lodano, sono macigni quando insultano."? Justifique.

2) Segundo a autora, quais seriam as possíveis consequências do discurso de ódio?

3) De acordo com o texto, a quem se dirige, geralmente, o discurso de ódio? Você concorda?

4) Você considera que o discurso de ódio é causado pela internet e só existe nesse contexto? Qual a opinião da autora sobre essa questão?

5) Quais as possíveis estratégias práticas apresentadas no texto para combater o discurso de ódio? Você concorda com elas? 
Atividade de pós-leitura: o professor ou professora pede aos aprendizes que confeccionem propostas que considerem eficientes para combater o discurso de ódio. A atividade pode ser feita em língua materna ou na língua-alvo, de acordo com o perfil dos alunos e com os objetivos do curso em que se insere.

\section{Licenças de uso:}

Insumos utilizados:

Conteúdos de Voci Globali: Creative Commons (CC - BY 4.0). Indicado no site Imagens: Creative Commons (CC - BY NC ND - equivalente). Informado pelos autores.

Sequência: (c) (†) Este trabalho está licenciado com uma Licença Creative Commons -

Recebido: 3/01/2018

Aceito: 18/07/2018 